\title{
Improving Optical Transmission of Indium Tin Oxide (ITO) thin films prepared by Femtosecond Laser ablation
}

\author{
A. M. Abd El-Karim*, M. G. Khafagi", Wael H. Eisa*, A. Shabaka*, \\ and $\mathrm{H}$. Talaat ${ }^{\S}$ \\ *Spectroscopy Department, Physics Division, National Research Center \\ $\S$ Physics Department, Faculty of Science, Ain Shams University
}

\begin{abstract}
Indium-tin-oxide (ITO) thin films have been grown by ultrafast femtosecond laser ablation technique. The films prepared at different deposition temperature $\left(24\right.$ to $\left.400{ }^{\circ} \mathrm{C}\right)$ then annealed at $400{ }^{\circ} \mathrm{C}$ for $1 \mathrm{~h}$ under vacuum. The structural, optical, and electrical properties of ITO films were studied as a function of the substrate deposition temperature and compared to the annealed films. The increase in the deposition temperature resulted in an increase in the crystallinity as estimated from the preferential direction of ITO (222), optical transmission also increases, and electrical sheet resistance decreases. Annealing at $400^{\circ} \mathrm{C}$ for $1 \mathrm{~h}$ under vacuum, cause further increase in the crystallinity, optical transmission and decrease in the electrical sheet resistance. These results may help to increase the efficiency of the photovoltaic cells.
\end{abstract}

\section{Introduction}

Transparent conducting oxide films have been used extensively in the electronic industry, it has been widely utilized as an essential part of many optoelectronic devices ${ }^{[1-6]}$ due to their unique transparent and conducting properties ${ }^{[1-6]}$. Among the extensively used transparent conducting oxides, Indium tin oxide (ITO) thin films is one of the prominent materials that can be used as a transparent electrode, particularly in solar cell applications ${ }^{[6]}$. This is due to its superior of relatively high electrical conductivity, high optical transparency over the visual region of electromagnetic spectrum, chemical stability and excellent adhesion to substrates ${ }^{[7]}$. The low resistivity value of ITO films is due to a high carrier concentration because the Fermi level $\left(\mathrm{E}_{\mathrm{F}}\right)$ is located above the conduction level $\left(\mathrm{E}_{\mathrm{C}}\right)$. This degeneracy is caused by both oxygen vacancies and substitutional tin dopants created during film deposition 
${ }^{[1,5]}$. The high transmission in the visible and near-IR regions is attributed to its wide band gap $\mathrm{E}_{\mathrm{g}}(3.5-4.3 \mathrm{eV}){ }^{[1-3,8]}$

There are many fabrication techniques for the growth of thin ITO film employed such as thermal evaporation [9], chemical vapor deposition [9], magnetron sputtering ${ }^{[9-11]}$, vacuum evaporation ${ }^{[9,12]}$, spray pyrolysis ${ }^{[9,10,13]}$, electron-beam evaporation ${ }^{[14]}$, ion-beam sputtering ${ }^{[12]}$, and pulsed laser deposition (PLD). The last technique has been proved to be a very effective method to deposit high quality films. A broad class of materials, ranging from semiconductors to superconductors with high critical temperature have been prepared ${ }^{[15]}$. In recent years the increasing availability of ultrashort pulsed laser has opened new possibilities in the PLD field, resulting in the deposition of near stoichiometric films also in the case of oxides ${ }^{[15]}$. However ITO thin films prepared by pulsed laser deposition using ultrafast femtosecond laser technique have gained less attention, which is the subject of this study. Annealing normally is expected to improve the physical properties of ITO thin films, and the presence of oxygen during annealing may vary the sheet resistance ${ }^{[1,4,16]}$.

In this study, we investigate the effect of the annealing process of ITO thin films in the presence of controlled amount of oxygen under vacuum.

\section{EXPERIMENTAL}

ITO thin films were deposited on glass substrates using a Titanium sapphire laser with a wavelength of $800 \mathrm{~nm}$ and pulse duration of $40 \mathrm{fs}$ at 1000 $\mathrm{Hz}$ delivered an average power of 700 mwatt. Schematic diagram of the experimental setup is shown in Figure (1). The laser was focused through a lens of focal length $50 \mathrm{~cm}$ onto a rotating target at a $45^{\circ}$ angle of incidence. The target-substrate distance was kept at $9 \mathrm{~cm}$. The substrate with a stainless steel mask was attached to a substrate holder, which was heated by a quartz lamp. The substrate temperature was monitored with a thermocouple at all times. ITO (Purity, 99.99\% - Sigma-Aldrich) was used as a starting material. The powders were mixed with iso-butanol as a binder molecule then pressed into a 1-in.diam pellet, and then sintered at $900{ }^{\circ} \mathrm{C}$ for $6 \mathrm{~h}$ in an oven. The glass substrates were cut in dimensions $(1 \mathrm{~cm} \times 2 \mathrm{~cm})$ then left in a chromic acid (potassium dichromate + sulphoric acid) for $48 \mathrm{~h}$ and washed by distilled water then cleaned in an ultrasonic cleaner for $10 \mathrm{~min}$ with acetone and then ethanol. Substrate deposition temperatures were varied between $\left(24-400{ }^{\circ} \mathrm{C}\right)$, after the deposition process the films were annealed at $400{ }^{\circ} \mathrm{C}$ for $1 \mathrm{~h}$ under vacuum. Crystallographic, optical, and electrical properties are determined before and after annealing. X-ray diffraction (XRD) (Panalytical - EmpyreanNetherlands) was used to characterize both and the grain size of the films. The optical transmission measurements were carried out using an UV-visible-near- 
IR spectrophotometer (V-570 UV/VIS/NIR Jasco Spectrophotometer). The sheet resistance $\left(R_{s}\right)$ measurements were performed using a 4-point probe (Model 1906 Computing Multimeter, Thurlby Thander). All values of sheet resistance were determined as an average of three measurements for each film. The film thickness was measured by a stylus profilometer (Tektak 150).

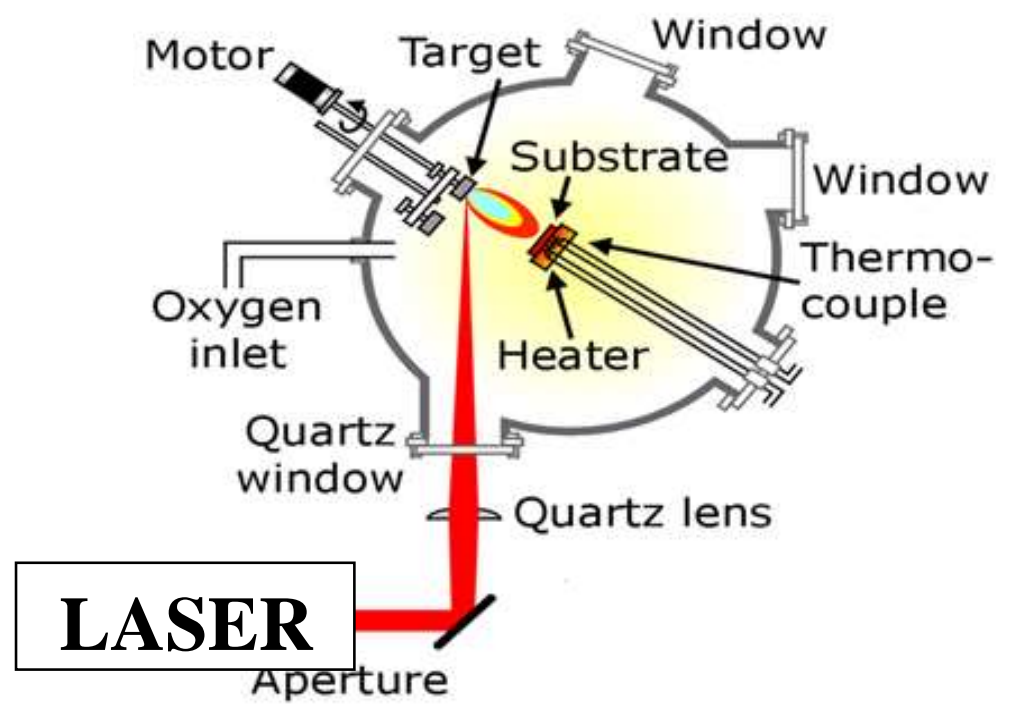

Figure (1): Schematic Diagram of Pulsed Laser Deposition Technique.

\section{RESULTS AND DISCUSSION}

\section{1 . X-ray Diffraction Analysis}

The XRD patterns of ITO films grown at different substrate deposition temperatures $(24,100,400){ }^{\circ} \mathrm{C}$ before the annealing process are shown in Figure (2). it is clear that the ITO film deposited at room temperature $\left(24{ }^{\circ} \mathrm{C}\right)$ is amorphous. As the deposition temperature was increased up to 400 ${ }^{\circ} \mathrm{C}$, diffraction peaks as shown appeared, that are indexed to planes (211), (222), (400), (441) and (622). These planes corresponds to polycrystalline cubic ITO according to JCPDS (89-4597) giving the structured formula $\left(\operatorname{In}_{1.875} \operatorname{Sn}_{0.125}\right) \mathrm{O}_{3}$. As the substrate deposition temperatures were increased the crystallinity as it can be seen from the preferential growth (222) increase. This dependence of the film's quality on the growth temperature can be attributed primarily to the mobility of the atoms during the deposition and the growth. At higher substrate temperature, the species have enough mobility to arrange the atoms at suitable positions in the crystalline cell which can lead to a decrease of the oxygen and indium vacancies. As a result, the density of the defects is reduced and higher crystallinity films are grown ${ }^{[17,18]}$. 


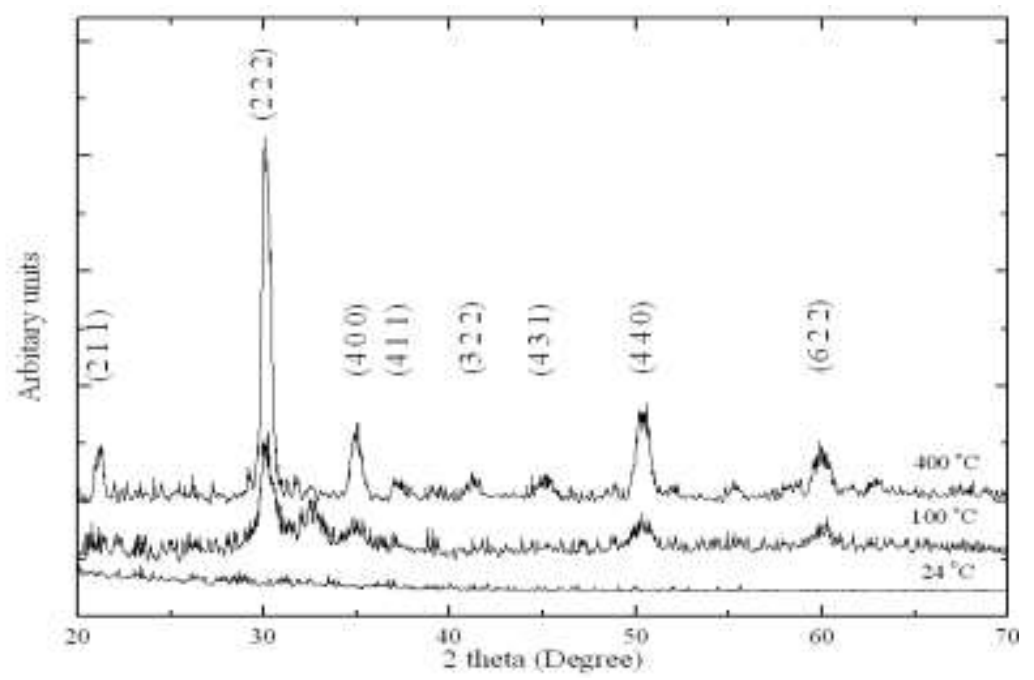

Figure (2): X-ray spectra of ITO thin films for samples prepared at deposition temperatures $\left(24,100\right.$ and $\left.400{ }^{\circ} \mathrm{C}\right)$ under vacuum base pressure $10^{-6}$ torr.

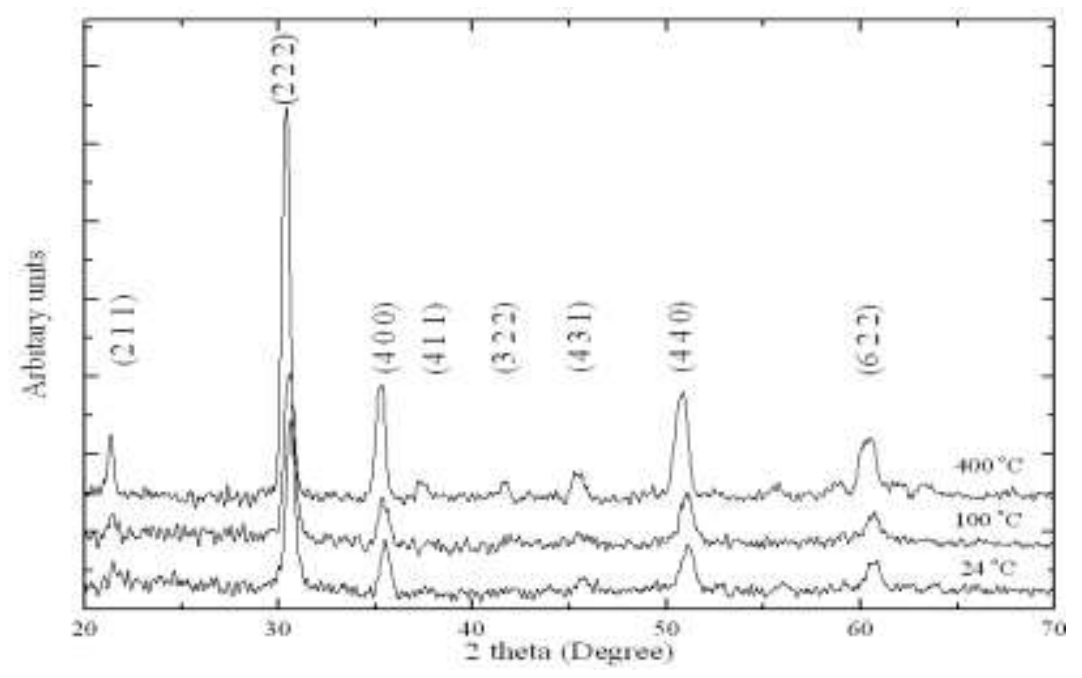

Figure (3): X-ray spectra of ITO selected thin film samples after the annealing at $400{ }^{\circ} \mathrm{C}$ for $1 \mathrm{~h}$ under vacuum.

Figure (3) shows the X-ray diffraction pattern of the ITO thin films after the annealing process. The peak intensity of ITO in XRD patterns is increased as a result of the increase in the crystallinity as compared the preferential growth (222). It is to be observed that the crystalline structural and 
shape weren't affected by the vacuum annealing process. The annealing process could enhance the activation energy of the surface as a result, the constituent atoms may occupy the correct sites in the crystal lattice and grains since the lower surface energy becomes larger at a high temperature ${ }^{[19]}$.

The X-ray diffraction pattren of the as-deposited film at $100{ }^{\circ} \mathrm{C}$ before the annealing shows an anomalous peak at $2 \theta=33^{\circ}$, which is indexed to the plane (101) of metallic indium, present in "non-stoichiometric In-rich" ITO film totally disappeared after the annealing process.

the grain size of the crystallites can be measured from scherrer equation [7].

$$
\mathrm{D}=\mathrm{k} \lambda / \beta \cos \theta
$$

where $\beta$ is the full width at half maximum (FWHM) of the peak corresponding to e tplane (222), $\mathrm{k}$ is the so-called shape factor which usually takes a value of about 0.9 or 1 , and $\theta$ is the angle obtained from $2 \theta$ value corresponding to maximum intensity peak in XRD pattern.

The calculated grain size of the crystallites using the above formula before and after the annealing process was tabulated in Table (1). From this table, it can be noted that the grain size of the particles increases as the deposition temperature increases and increasing further with the annealing process, which is attributed to the greater mobility and surface diffusion of the particles.

Table (1): Grain size of ITO thin films prepared under different deposition temperatures $\left(24,100\right.$ and $\left.400{ }^{\circ} \mathrm{C}\right)$ before and after the annealing at $400{ }^{\circ} \mathrm{C}$ for $1 \mathrm{~h}$ under vacuum.

\begin{tabular}{|c|c|c|}
\hline $\begin{array}{c}\text { Deposition } \\
\text { Temperature } \\
\left({ }^{\circ} \mathrm{C}\right)\end{array}$ & $\begin{array}{c}\text { Grain size before the } \\
\text { annealing process } \\
(\mathrm{nm})\end{array}$ & $\begin{array}{c}\text { Grain Size after the } \\
\text { annealing process } \\
(\mathrm{nm})\end{array}$ \\
\hline 400 & 19.40 & 22.55 \\
\hline 100 & 10.76 & 16.70 \\
\hline 24 & - & $\mid 9, \mathrm{r}$ \\
\hline
\end{tabular}




\subsection{Optical properties}

The transparency of the ITO films was routinely monitored by visual inspection of the prepared samples as well as by measuring the UV-VIS-NIR spectra. The out looking of the prepared samples exhibits an interesting example of color variation with increase the substrate deposition temperature and also after the annealing process. For deposition temperatures 24 and 100 ${ }^{\circ} \mathrm{C}$, the prepared films show black color. This blackness disappears as the deposition temperature increases as well as after the annealing treatment.

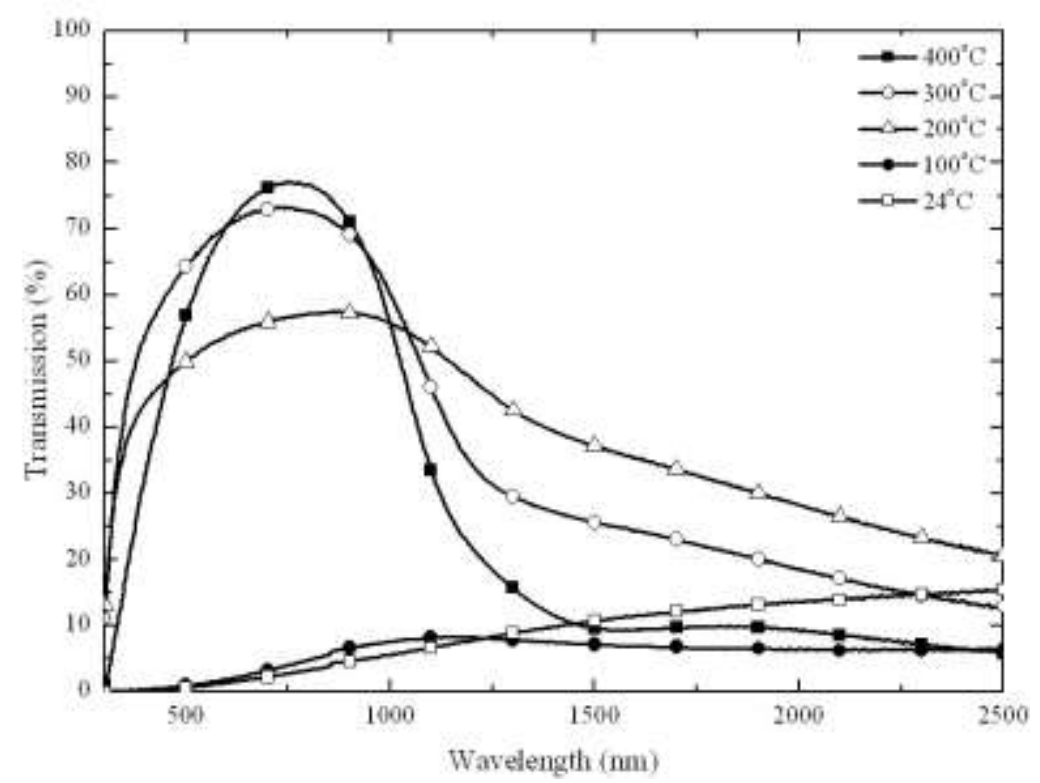

Figure (4): UV-Vis-NIR transmission spectra of ITO thin films prepared at different deposition temperatures. 


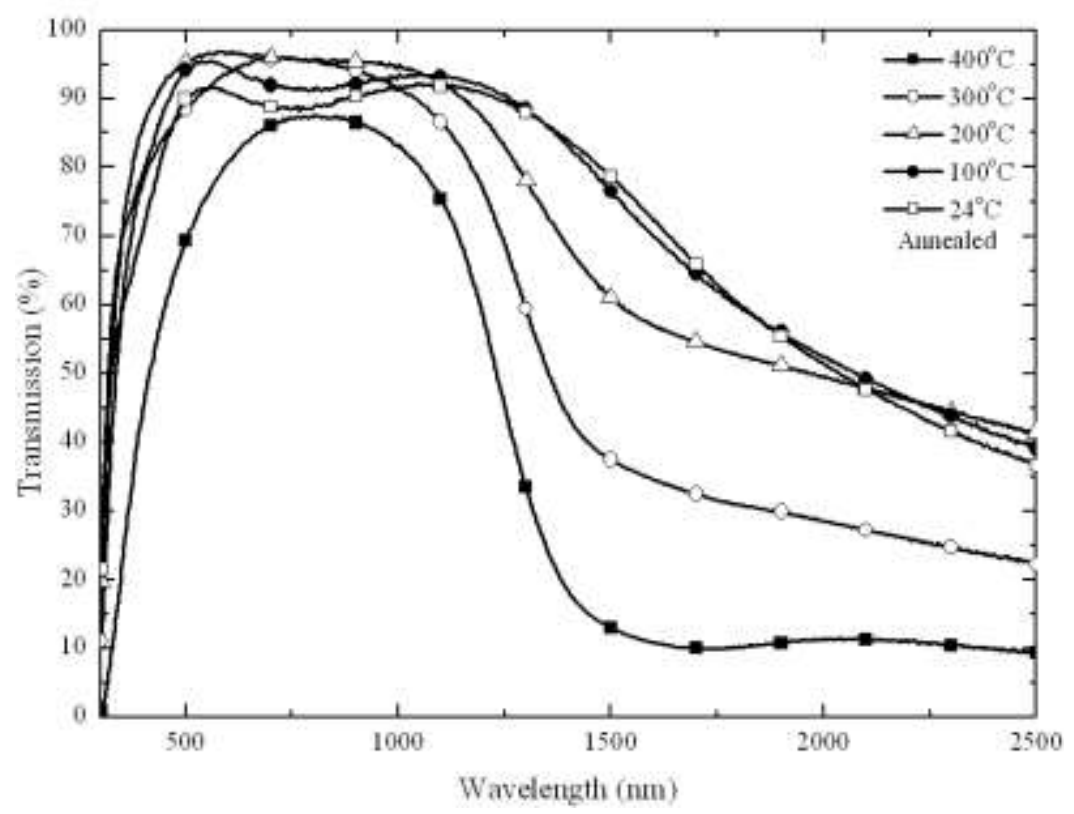

Figure (5): UV-VIS-NIR transmission spectra of ITO thin films prepared at different deposition temperatures after the annealing at $400{ }^{\circ} \mathrm{C}$ for $1 \mathrm{~h}$ for under vacuum.

Figure (4) and Figure (5) show the UV-VIS-NIR spectra of ITO thin films prepared at the indicated deposition temperatures before and after the annealing process respectively. The behavior of the average transmission in the optical range (400-800) nm before and after the annealing treatment depicted in Figure (6). The transmission of the samples deposited at 24 and $100{ }^{\circ} \mathrm{C}$ show a dramatic enhancement upon the annealing treatments. These samples were initially opaque and become colorless after the annealing process. Reflecting the crucial role of the annealing treatment in improving the optical properties of the ITO film. 


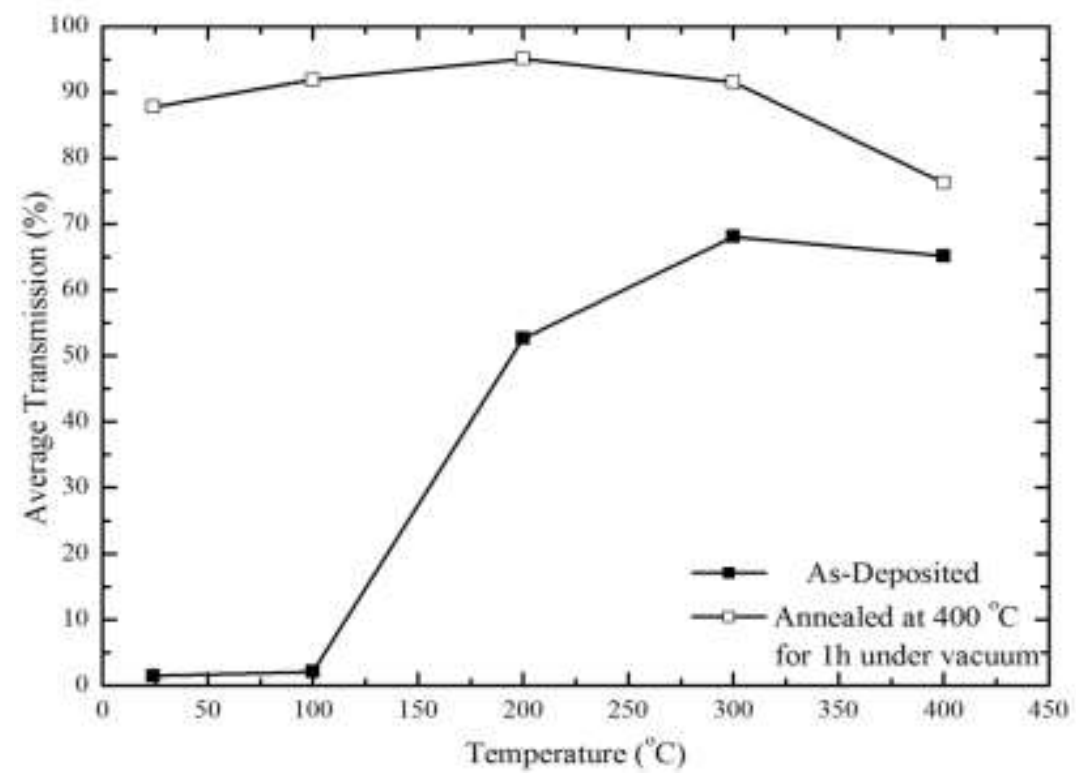

Figure (6): Average transmission spectra of ITO thin films at the optical range (400-800) $\mathrm{nm}$ prepared at different deposition temperature before and after annealing at $400{ }^{\circ} \mathrm{C}$ for $1 \mathrm{~h}$ for under vacuum.

The improvement of optical properties due to the annealing treatment process is understood in terms of the formation and the crystallization of the ITO films. Higher temperature heat treatment leads to a better crystallization and lower level of defects near the grain boundaries, thus resulting in the improvement of structural homogeneity and the decrease of light reflection and scattering ${ }^{[20,21]}$.

\subsection{Electrical properties}

Figure (7) shows that the sheet resistance of the ITO films deposited at different temperatures $\left(24-400{ }^{\circ} \mathrm{C}\right)$ before and after annealing at $400{ }^{\circ} \mathrm{C}$ for $1 \mathrm{~h}$ under vacuum. The sheet resistance decays sharply as the substrate deposition temperature increase and show another decrease after the annealing process.

The enhancement of the electrical conductivity of the films with increasing the deposition temperature is associated with the effect of thermally induced crystallization ${ }^{[4]}$. From our XRD, it was observed that the crystalline distortion decreases with the annealing process, and the grain size along sample surface increases with the annealing treatment. The growth of the grain size results in smaller grain boundary, consequently to a smaller grain boundary 
scattering ${ }^{[1,4,22,23]}$. This leads to a better transport of the electrons and higher conductivity.

Furthermore the electrical conductivity is enhanced on the annealing process. The obtained low sheet resistance could be attributed to improved crystalline nature upon annealing. In addition, the annealing process may result in more tin atoms diffusing from grain boundaries and interstitial lattice locations to regular $\operatorname{In}_{2} \mathrm{O}_{3}$ lattice location.

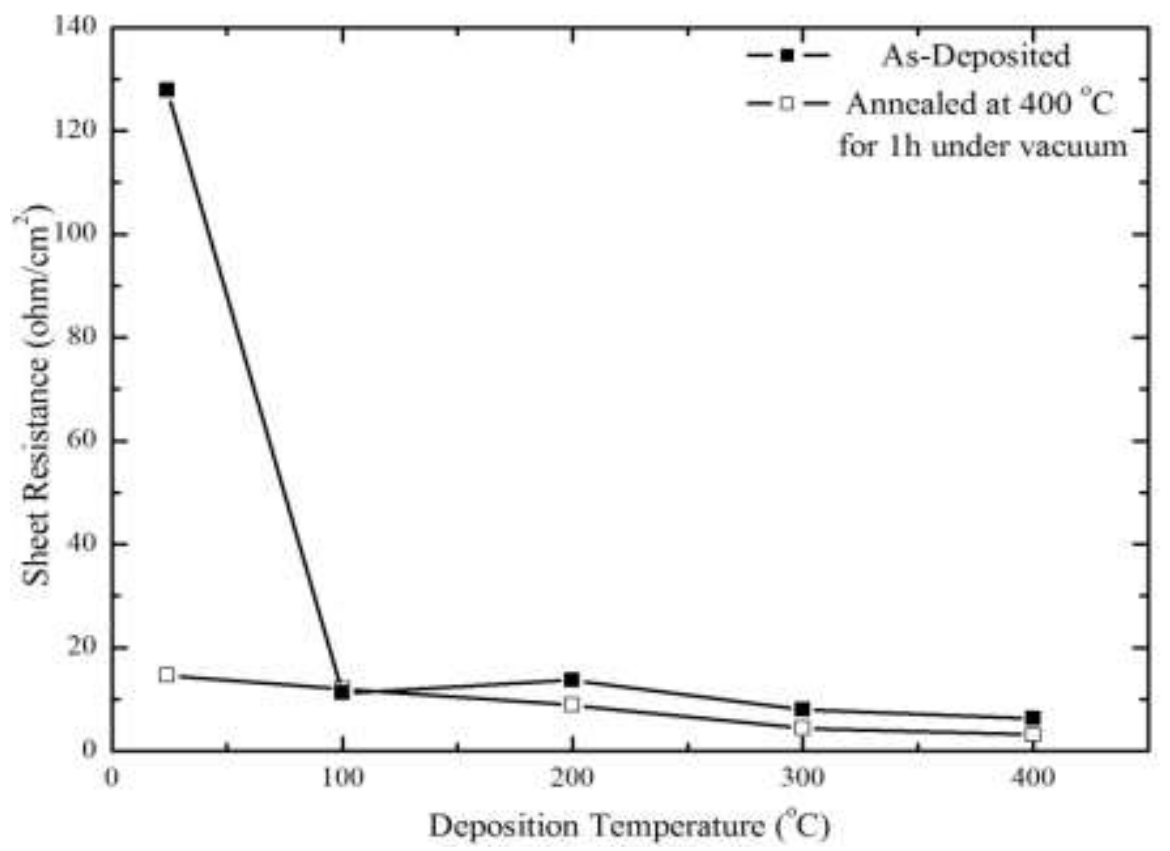

Figure (7): Sheet resistance of ITO thin films prepared at vacuum base pressure $10-6$ torr under different deposition temperatures before and after the annealing process.

\section{CONCLUSION}

High-quality ITO films have been deposited on glass substrates by Femtosecond Laser ablation. As the substrate deposition temperature increased and further annealing the peak intensity of the preferential growth (222) of ITO increased, thus the metallic In is totally infused in ITO crystal lattice. The preferential growth (222) direction related to the stoichiometric ratio of $\operatorname{In}_{2} \mathrm{O}_{3}$. The average transmission shows an enhancement in the optical range (400-800) $\mathrm{nm}$ as the deposition temperature increased, then show a noticeable increase after the vacuum annealing process. Increasing the temperature during and after 
the deposition process created more Sn donors and oxygen vacancies, and thus increased conductivity of the films.

\section{References}

1. H. Kim, C. M. Gilmore, A. Pique', J. S. Horwitz, H. Mattoussi, H. Murata, Z. H. Kafafi, and D. B. Chrisey, Electrical, optical, and structural properties of indium-tin-oxide thin films for organic lightemitting devices. JOURNAL OF APPLIED PHYSICS 1999. 86(11): p. $6451-6461$.

2. A. Dixit, C. Sudakar, R. Naik, V. M. Naik, and G. Lawes, Undoped vacuum annealed $\mathrm{In}_{2} \mathrm{O}_{3}$ thin films as a transparent conducting oxide. APPLIED PHYSICS LETTERS, 2009. 95: p. 192105 1-3.

3. S.J. Wakeham, M.J. Thwaites, B.W. Holton, C. Tsakonas, W.M. Cranton, D.C. Koutsogeorgis, and R. Ranson, Low temperature remote plasma sputtering of indium tin oxide for flexible display applications. Thin Solid Films, 2009. 518 p. 1355-1358.

4. Jin Baek Choi, Jong Hoon Kim, Kyung Ah Jeon, and Sang Yeol Lee, Properties of ITO films on glass fabricated by pulsed laser deposition. Materials Science and Engineering, 2003. B102: p. 376-379.

5. Shui-Yang Lien, Characterization and optimization of ITO thin films for application in heterojunction silicon solar cells. Thin Solid Films 2010. 518 p. S10-S13.

6. Juan M. Camacho, R. Castro-Rodrı'guez, and J.L. Peñ a, Transparent conductive oxide thin films of CdTe-doped indium oxide prepared by pulsed-laser deposition. Optics \& Laser Technology 2008. 40: p. 895900.

7. M.M. El-Nahass, and E.M. El-Menyawy, Thickness dependence of structural and optical properties of indium tin oxide nanofiber thin films prepared by electron beam evaporation onto quartz substrates. Materials Science and Engineering B, 2012. 177 p. 145- 150.

8. Birgitte Thestrup, Jørgen Schou, Arne Nordskov and Niels B. Larsen Electrical and optical properties of thin indium tin oxide films produced by pulsed laser ablation in oxygen or rare gas atmospheres. Applied Surface Science 1999. 142: p. 248-252.

9. Zhaohui Qiao, FABRICATION AND STUDY OF ITO THIN FILMS PREPARED BY MAGNETRON SPUTTERING, thesis Duisburg-Essen University 2003.

10. Shabbir A. Bashar, Study of Indium Tin Oxide (ITO) for Novel Optoelectronic Devices, thesis London University 1998.

11. Jow-Lay Huang, Yin-Tsan Jah, Ching-Yun Chen, Bao-Shun Yau, and Su-Shia Lin, Reactive Magnetron Sputtering of Indium Tin Oxide Films on Acrylics-Electrical Resistivity and Optical Properties. 2000. 9(4): p. 424-427. 
12. R.P. Howson, I. Safi, G.W. Hall, N. Damon, Sputtering of indium-tin oxide. Nuclear Instruments and Methods in Physics Research 1997. B I21: p. 96- 101.

13. H. H. AFIFY, F. S. TERRA, and R. S. MOMTAZ, Substrate temperature effects on the tin oxide films prepared by spray pyrolysis. JOURNAL OF MATERIALS SCIENCE. MATERIALS IN ELECTRONICS, 1996. 7: p. 149 -153.

14. Mika Yamaguchi, Ari Ide-Ektessabi, Hiroshi Nomura, Nobuto Yasui, Characteristics of indium tin oxide thin films prepared using electron beam evaporation. Thin Solid Films, 2004. 447 - 448: p. 115-118.

15. R. Teghil, D.F., A. Galasso, A. Giardini, V. Marotta, G.P. Parisi, A. Santagata, P. Villani, Femtosecond pulsed laser deposition of nanostructured ITO thin films. Materials Science and Engineering 2007. C 27: p. 1034-1037.

16. A. V. SINGH, MANOJ KUMAR, R. M. MEHRA, AKIHIRO WAKAHARA, AND AKIRA YOSHIDA, Al-doped zinc oxide (ZnO:Al) thin films by pulsed laser ablation. Indian Institute of Science, 2001. 81: p. 527 - 533.

17. S. H. Bae, S. Y. Lee, B. J. Jin, and S. Im, Applied Surface Science, 2001. 169-170: p. 525-528.

18. D. Beena, K. J. Lethy, R. Vinodkumar, A. P. Detty, V. P. Mahadevanpillai,and V. Ganesan, Optoelectronics and Advanced Materials, 2011.5 p. $1-11$.

19. J. Sun, T. Yang, G. Du, H. Liang, J. Bian, and L. Hu, Applied Surface Science, 2006. 253: p. 2066-2070.

20. Karasawa, and T. Miyata Thin Solid Films, 1993. 233 p. 135-139.

21. Z.H Li, Y.P Ke, and D.Y Ren, Trans Nonferrous Met. Soc. China, 2008. 18: p. 366-371.

22. Jong Hoon Kim, Byung Du Ahn, Choong Hee Lee, Kyung Ah Jeon, Hong Seong Kang, Gun Hee Kim, and Sang Yeol Lee, Enhancement in electrical and optical properties of indium tin oxide thin films grown using a pulsed laser deposition at room temperature by two-step process. Thin Solid Films, 2007. 515 p. 3580-3583.

23. Robert Eason, PULSED LASER DEPOSITION OF THIN FILMS. John Wiley \& Sons, Inc, 2007. 